\title{
Association between Potentially Inappropriate Medication Use and Chronic Diseases in the Elderly
}

\author{
Tzu-Chueh Wang ${ }^{1} \oplus$, Pou-Jen Ku ${ }^{2}$, Hai-Lin Lu ${ }^{3}$, Kung-Chuan Hsu ${ }^{4} \oplus^{\circ}$, Damien Trezise ${ }^{5}$ \\ and Hue-Yu Wang 1,6,*(D) \\ 1 Department of Pharmacy, Chia Nan University of Pharmacy and Science, Tainan City 71710, Taiwan; \\ tzchwa@mail.cnu.edu.tw \\ 2 Taiwan Pharmacist Association, Taipei City 10452, Taiwan; kupoujen@yahoo.com.tw \\ 3 Department of Information Management, Chia Nan University of Pharmacy and Science, Tainan \\ City 71710, Taiwan; hllu2719@gmail.com \\ 4 Giraffe Pharmacy, Tainan City 71049, Taiwan; gighv206@gmail.com \\ 5 Department of Applied Foreign Languages, Chia Nan University of Pharmacy and Science, \\ Tainan City 71710, Taiwan; damien@mail.cnu.edu.tw \\ 6 Department of Pharmacy, Chi-Mei Medical Center, Tainan City 71004, Taiwan; cmh5500wang@gmail.com \\ * Correspondence: tzchwa@mail.cnu.edu.tw; Tel.: +886-6-2664911 (\#2226)
}

Received: 18 May 2019; Accepted: 17 June 2019; Published: 20 June 2019

\begin{abstract}
Long-term continuous exposure to potentially inappropriate medications (PIMs) can lead to adverse events in the elderly. However, the effects of long-term exposure of the elderly to PIM and the relationship between PIM and chronic diseases remain unclear. The objective of this study was to investigate the continuous use of PIMs in a community-dwelling elderly population. A cross-sectional population-based study was conducted using community pharmacy-filed dispensing records from the Hcare system. Twenty-three community pharmacies were sampled from 2013 to 2015 to obtain records of patients above 65 years-old with continuous prescriptions. PIM were identified according to the 2015 Beers Criteria. The prevalence of patients using PIM was highest in patients with co-morbid mental disorders $(40.05 \%)$, followed by neurological system disorders $(28.91 \%)$. Patients who were prescribed a PIM were more than three times as likely to have a mental disorder as those (odds ratio 3.16, 95\% confidence interval: 3.06-3.28) with non-chronic diseases. The most prescribed PIM agents were central nervous system drugs $(53.16 \%)$, and benzodiazepines $(35.15 \%)$. Patients with mental disorders had the highest rate of long-term persistent PIM exposure, with benzodiazepines being the most frequently dispensed. Drug safety concerns should be closely monitored in elderly patients with the abovementioned conditions.
\end{abstract}

Keywords: Beers Criteria; chronic disease; elderly; Potentially Inappropriate Medication

\section{Introduction}

Studies show that the use of pharmaceuticals in developed countries increases with age and that elderly people often take at least three prescription drugs simultaneously [1,2]. Even in developing countries, the proportion of elderly who take at least one drug daily is as high as $85-90 \%$ [3-5]. Because of the varying physiological, pharmacokinetic and pharmacodynamic characteristics of the elderly, it has become difficult for physicians to prescribe drugs. This problem can result in frequent prescriptions of potentially inappropriate medications (PIMs). The higher the number of drugs taken by an elderly patient, the greater the likelihood of the patient being subjected to potentially inappropriate drug therapy, consequently increasing the risk of drug-related adverse reactions $[6,7]$. The current rate of PIM prescription to the elderly is an important public health issue. Not only does it affect 
patients' morbidity, hospitalization and mortality rates, but adverse events from PIMs add significantly to healthcare cost $[8,9]$.

The Beers Criteria constitute a consensus-based list of PIMs for individuals aged 65 years and older. They were first developed for nursing home residents in 1991 and have been updated twice, in 1997 and 2003, for use in the general elderly population based on new clinical evidence [10]. In 2015, the list of select drugs that should be avoided or subjected to dosage adjustments according to patient's kidney function or select drug-drug interactions harmful to older adults was updated [11]. A new version was released in 2019, and differences between this and the 2015 version will be described in the discussion section. Studies on physicians prescribing PIM to the elderly and use of the Beers Criteria have been published worldwide, including cost [12,13], risk factors [14,15], prevalence, and PIM-related effects $[9,16,17]$.

Taiwan's National Health Insurance (NHI) system is a specialist treatment system, in which insured persons have unrestricted choices of hospitals and unlimited numbers of visits. From the first consultation, doctors can issue prescriptions for chronic diseases that allow patients to utilize community pharmacies for three consecutive months without having to return for a follow-up consultation. This practice exposes the elderly to an increased risk of PIM. Previous studies have investigated the prevalence of PIM amongst the elderly [16], risk of adverse reactions caused by PIM in chronic disease treatment [18], safety of single-category PIMs (anti-cholinergics) used by elderly patients and dangers of PIM use in elderly patients in continuous care $[19,20]$. The results highlight the seriousness of this issue, showing that PIM prescriptions are associated with potential risks to the elderly. The proportion of elderly people with at least one chronic disease is about 50\% [21-23], and they generally require long-term use of medications to manage symptoms. This raises two questions worthy of further investigation: (1) What proportion of elderly people is subject to long-term exposure to PIM? (2) What is the relationship between PIM prescription and chronic diseases already diagnosed?

The claims data including prescriptions filed by authorized community pharmacies were used to investigate the risk of long-term continuous (three-year period) exposure to PIM amongst patients aged 65 years or older with chronic diseases. This study aimed to investigate the relationships between PIM and chronic diseases and the distribution of PIMs.

\section{Materials and Methods}

\subsection{Data Sources and Study Design}

This was a population-based study using community pharmacy-filed dispensing records in the Community Pharmacy Care Management System (Hcare) of the Taiwan Pharmacists Association from January 1, 2013, to December 31, 2015. Population data were drawn from a random sample of eligible community pharmacies that met the research criteria.

The initial selection conditions included pharmacies that filled an average of more than 900 prescriptions per month. Pharmacies in which an undue proportion of the prescriptions filled came from a single medical institution, such as more than $50 \%$ of total prescriptions being issued by one hospital, were excluded to reduce sampling bias.

A total of 23 community pharmacies met the selection criteria and were included in the study. Information in claims data files was obtained after removing identifying personal information, and included monthly claims data of the community pharmacy, age and sex of the insured, hospital and department that issued the prescription, patient's diagnosis (classified according to the International Classification of Diseases, 9th, ICD-9), medication dispensed (including the generic name, dose, administration method, number of days of prescription and date of issue) and service center. We included data for oral medications and insulin. This study used the 2015 Beers Criteria to determine whether medicines prescribed by doctors were PIMs or not. 


\subsection{Study Population}

The research subjects were Taiwanese people aged 65 years or older who were insured under the Taiwan NHI and had received more than 28 consecutive days of prescriptions for chronic disease at an NHI-approved pharmacy. Subjects whose main diagnosis was a chronic disease were further classified into PIM and non-PIM groups after analysis of their prescriptions. Patients with non-chronic conditions that met the same criteria comprised the control group. The selection process according to demographic data is shown in Figure 1.

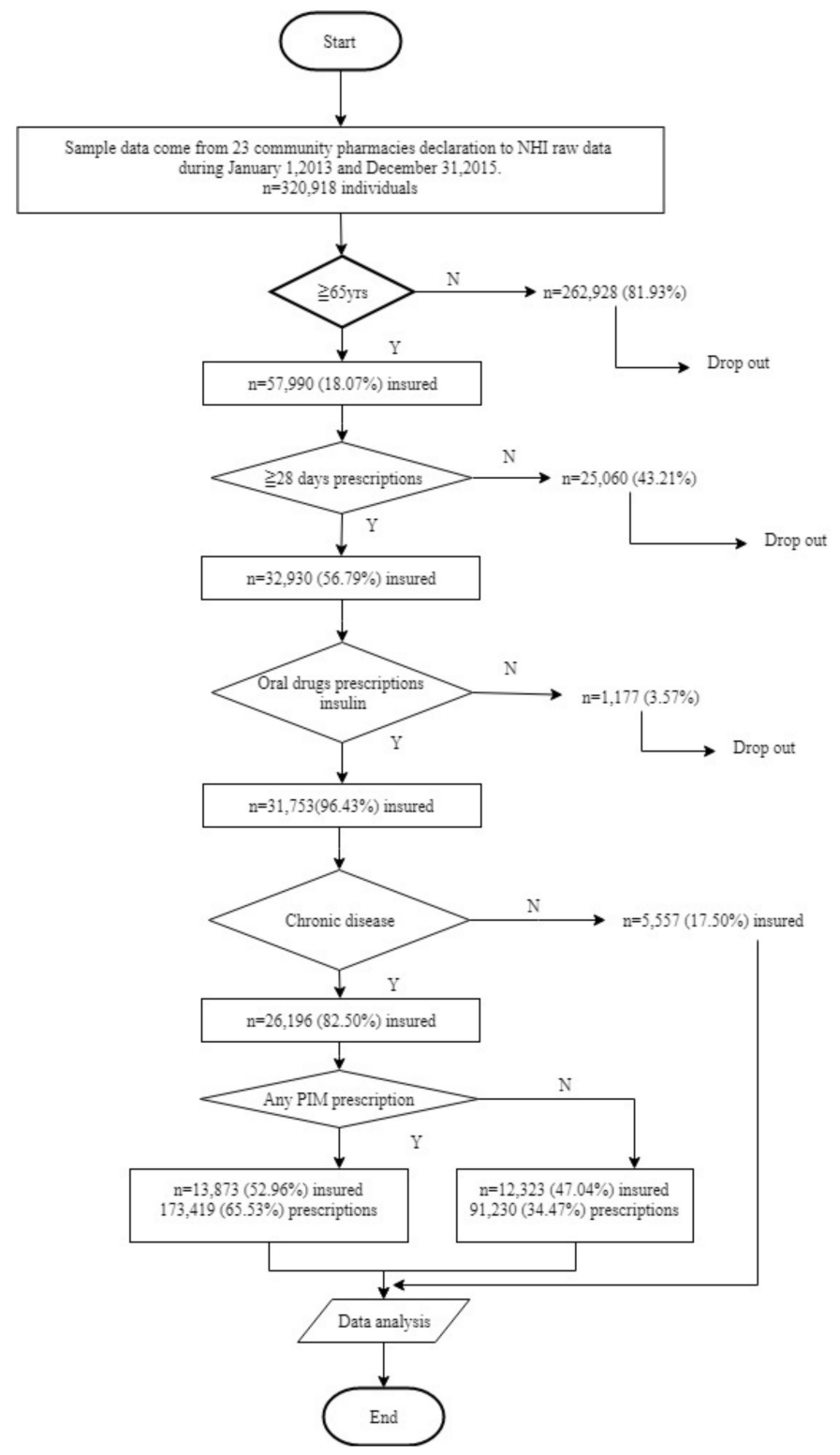

Figure 1. Flowchart of patient sample collection.

\subsection{Definitions of Terms}

Chronic diseases: Those that persist for more than three months or cause permanent injuries or conditions that persist due to illness or congenital complaints [24]. Chronic diseases in this study were classified according to the 16 major chronic disease categories recognized by the Taiwan Health Insurance Department [25].

Prescriptions: Prescriptions written by doctors that are valid for up to 30 days in Taiwan, and can only be filled once. Continuous prescriptions are available for patients with chronic diseases. 
Continuous prescriptions for chronic diseases: Prescriptions issued by physicians to patients diagnosed with chronic diseases that can be refilled up to three times, for up to 30 days each time.

National Health Insurance (NHI)-approved pharmacy: A community pharmacy that accepts continuous prescriptions for chronic diseases prescribed by hospitals or clinics.

Potentially inappropriate medication (PIM): Medications designated as potentially inappropriate for use in older adults according to the American Geriatrics Society's 2015 updated Beers Criteria (adults) [11].

Patients with PIM prescriptions: Any person who was prescribed at least one medication designated as a PIM during the study period.

Patients without PIM prescriptions: Any person who was never prescribed a PIM, as defined above.

\subsection{Measurements}

Subject data were compiled under fields including age, sex, prescription source, prescribing department, illness diagnosed and names of prescribed medications. The probability of prescriptions for chronic diseases causing patients to experience long-term exposure to PIM during the study period was designated as individual exposure to PIM (IE $\mathrm{IPIM}_{\mathrm{IP}}$ ). The formula for the $\mathrm{IE}_{\mathrm{IPM}}$ calculation is shown below as Formula (1):

$\mathrm{IE}_{\mathrm{IPIM}}=$ (number of PIM prescribed to an individual patient $\mathrm{I}_{\mathrm{PIM}} \div$ total number of medicines prescribed for that patient $\mathrm{I}_{\text {Total }}$ ) X100\%.

The incidence of IEIPIM in patients with chronic diseases exposed to different rates of PIM for extended periods was designated as RPIM (rate of PIM). The formula for calculating RPIM is shown below as Formula (2), and the number of PIM prescriptions for chronic diseases is as follows:

PIM I $\mathrm{I}_{\mathrm{CDpim}} \div$ total number of prescriptions for chronic diseases $\mathrm{I}_{\mathrm{CDTotal}} \mathrm{X} 100 \%$.

Using the odds ratio (OR), a comparison of the risk of PIM being prescribed to patients with any chronic disease and those with non-chronic diseases could be made under equivalent conditions. Finally, the most commonly prescribed PIMs were analyzed in terms of their distribution according to the 2015 Beers Criteria.

$$
\begin{gathered}
I E_{I P I M}=\frac{I_{\text {PIM }}}{I_{\text {Total }}} \times 100 \% \\
\mathrm{R}_{\text {PIM }}=\frac{I_{\text {CD pim }}}{I_{\text {CDTotal }}} \times 100 \%
\end{gathered}
$$

\subsection{Statistical Analysis}

Chi-square tests were used to determine the independence of categorical variables. Multivariate logistic regression analysis was performed to evaluate the association between each chronic disease and PIM prescriptions. The results are reported as ORs and 95\% confidence intervals (CI), after adjusting for potential confounding factors such as age, institutional level and medical department. Statistical significance was set at $\mathrm{p}<0.05$. All analyses were conducted using STATA software, version 14.2 (STATA Corp., College Station, TX, USA).

\subsection{Ethics Approval}

This study was approved by the Institutional Review Board of Chi-Mei Medical Center (IRB serial no. 10706-003). Data was converted from the Hcare system and hence the patients' personal information was deleted.

\section{Results}

\subsection{Subjects' Characteristics}

The process for identifying the data for this research is shown in Figure 1. A total of 320,918 insured persons' data files were retrieved from 23 Hcare community pharmacies, from which a total of 
13,873 insured persons met the inclusion criteria (elderly persons with chronic diseases who had been prescribed PIM). A total of 173,419 PIM prescriptions were identified (65.53\%).

Table 1 shows that the incidence of PIM prescriptions amongst elderly patients with chronic diseases increased with age and this correlation was significant $(p<0.001)$.

There was a significant positive correlation between the number of co-morbidities and the incidence of PIM prescriptions $(p<0.001)$. However, there was no significant correlation between sex and PIM prescriptions $(p=0.576)$. There was a correlation between polypharmacy prescriptions and the incidence of PIM, in that the incidence of PIM was lower when less than five medications were taken (approximately $31.98 \%$ vs. $57.66 \%$ ).

Table 1. Study participants' demographic and clinical characteristics.

\begin{tabular}{|c|c|c|c|}
\hline Characteristic & $\begin{array}{l}\text { Patients with PIM } \\
\text { Prescriptions } \\
(n=16,766)\end{array}$ & $\begin{array}{l}\text { Patients without PIM } \\
\text { Prescriptions } \\
(n=14,987)\end{array}$ & $p$-Value * \\
\hline Age & & & $<0.001^{* * *}$ \\
\hline $65-74$ years & $8130(48.49)$ & $8442(56.33)$ & $<0.001^{* * *}$ \\
\hline $75-84$ years & 6242(37.23) & 4889(32.62) & $<0.001^{* * *}$ \\
\hline$\geq 85$ years & 2394(14.28) & 1656(11.05) & reference \\
\hline Sex & & & 0.096 \\
\hline Male & $7620(45.45)$ & 6672(44.52) & \\
\hline Female & $9146(54.55)$ & $8315(55.48)$ & \\
\hline Department & & & $<0.001^{* * *}$ \\
\hline Cardiology & $4629(15.6)$ & $3248(16.97)$ & $0.022 *$ \\
\hline Chest & $1032(3.48)$ & $496(2.59)$ & $<0.001^{* * *}$ \\
\hline Endocrinology & $1696(5.72)$ & $1132(5.91)$ & 0.361 \\
\hline Family medicine & 3785(12.75) & 3574(18.67) & $<0.001^{* * *}$ \\
\hline Gastroenterology & $2040(6.88)$ & $612(3.2)$ & $<0.001^{* * *}$ \\
\hline Internal medicine & 3987(13.43) & 3961(20.7) & $<0.001^{* * *}$ \\
\hline Nephrology & $1053(3.55)$ & $456(2.38)$ & $<0.001^{* * *}$ \\
\hline Neurology & 3886(13.09) & $1528(7.99)$ & $<0.001^{* * *}$ \\
\hline Neurosurgery & $707(2.38)$ & $368(1.92)$ & $0.007^{* *}$ \\
\hline Orthopedics & $1528(5.15)$ & $1058(5.53)$ & 0.116 \\
\hline Others & $1945(6.55)$ & $1237(6.47)$ & reference \\
\hline Psychiatry & $1236(4.16)$ & $144(0.75)$ & $<0.001^{* * *}$ \\
\hline Surgery & $500(1.68)$ & $379(1.98)$ & $0.023 *$ \\
\hline Urology & $1655(5.58)$ & $945(4.94)$ & 0.048 * \\
\hline Number of chronic disease & & & $<0.001^{* * *}$ \\
\hline 1 & $4281(25.53)$ & 6495(43.34) & $<0.001^{* * *}$ \\
\hline 2 & $5197(31)$ & $4701(31.37)$ & $<0.001^{* * *}$ \\
\hline 3 & $3585(21.38)$ & $2619(17.48)$ & $<0.001^{* * *}$ \\
\hline 4 & $2116(12.62)$ & $862(5.75)$ & $<0.001^{* * *}$ \\
\hline$\geqq 5$ & $1587(9.47)$ & $310(2.07)$ & reference \\
\hline
\end{tabular}

Values are presented as $n(\%) .{ }^{*} \chi^{2}$ tests. ${ }^{*} p<0.05,{ }^{* *} p<0.01,{ }^{* * *} p<0.001$.

\subsection{Probability of Sustained Exposure to PIM Amongst Patients with Various Chronic Diseases}

Figure 2 shows in all chronic diseases, PIM was included in each prescription (100\% exposure) for a significant number of cases, with the highest incidences in mental $(40.05 \%)$, neurological $(28.91 \%)$, circulatory $(22.93 \%)$, and respiratory $(22.81 \%)$ conditions.

The distribution of the incidence of long-term continuous exposure to PIM of $>20 \%$ for four types of chronic diseases $(0 \%, 0 \%<x<100 \%, 100 \%)$ is shown in Figure 2. Patients with chronic diseases of the circulatory system had the highest probability of zero exposure to PIM (41\%), whilst the highest probability of $100 \%$ exposure to PIM occurred amongst patients with mental disorders (19.04\%). 


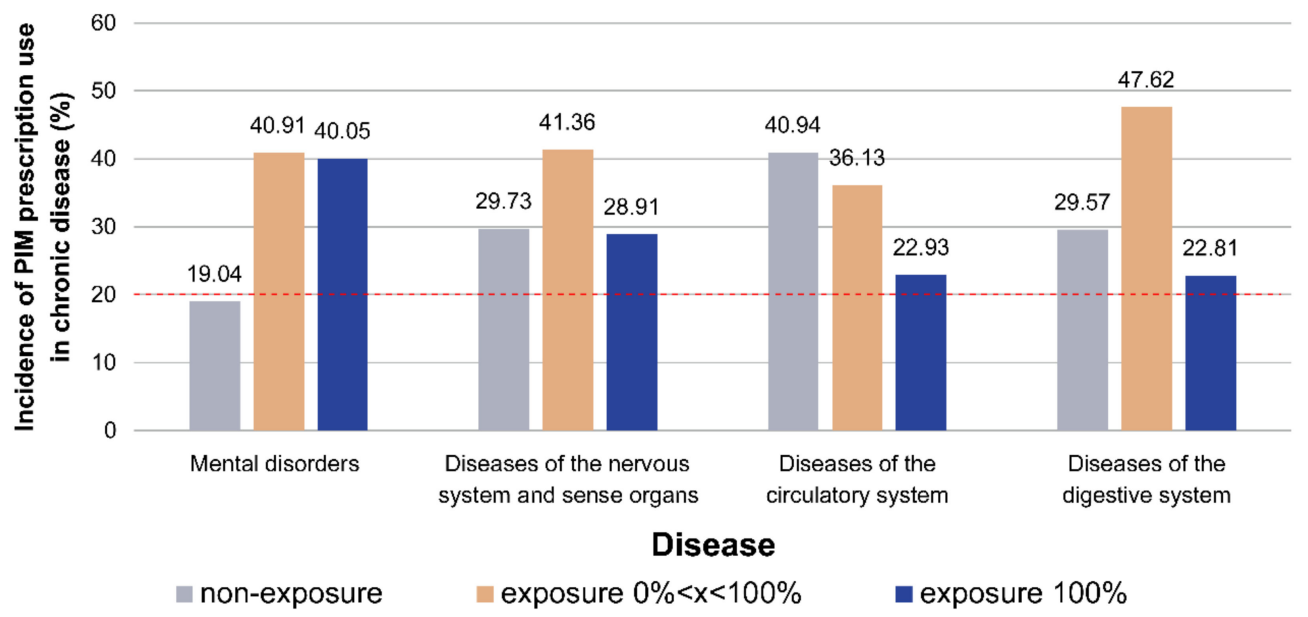

Figure 2. Chronic diseases for which there was a $100 \%$ continuous long-term exposure to PIM prescription rate of $>20 \%$, shown at exposure rates of $0 \%, 0 \%<x<100 \%$ and $100 \%$.

Table 2 shows that the top three chronic diseases in terms of the total number of prescriptions issued were endocrine and metabolic $(1,218,545)$, circulatory system $(109,119)$ and musculoskeletal system and connective tissue diseases $(45,063)$. However, the top three chronic diseases in terms of the incidence of PIM prescriptions were mental (55.85\%), neurological $(47.92 \%)$ and genitourinary system diseases $(43.4 \%)$.

Table 2. Comparison of $100 \%$ continuous exposure to PIM prescriptions, number of prescriptions, PIM prescription rate and OR by chronic disease type.

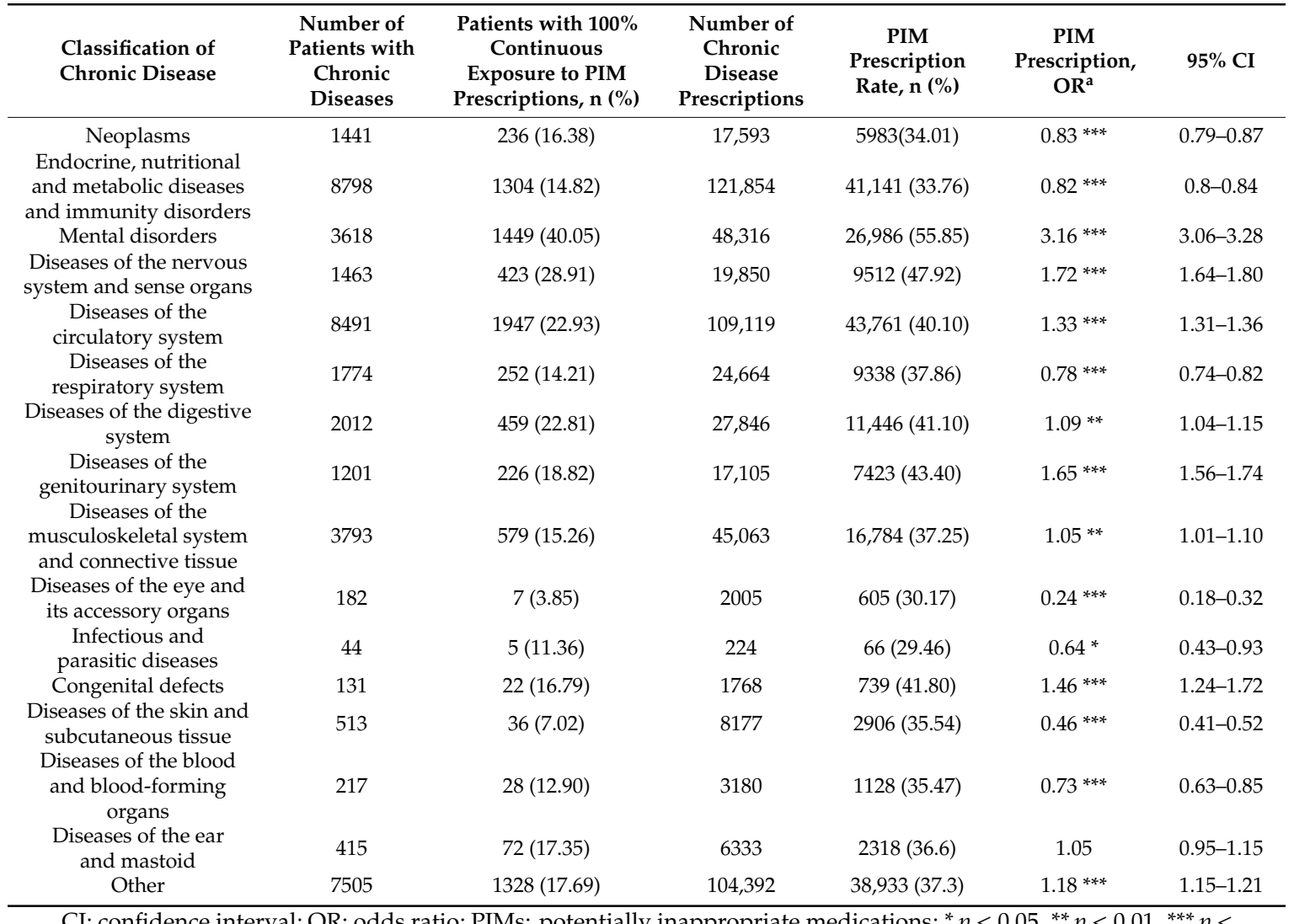

CI: confidence interval; OR: odds ratio; PIMs: potentially inappropriate medications; ${ }^{*} p<0.05,{ }^{* *} p<0.01,{ }^{* * *} p<$ 0.001 . 
When multivariate logistic regression analysis was used to compare the ORs of PIM prescriptions for chronic and non-chronic diseases, the ORs of PIM prescriptions for mental disorders was 3.16 times that of PIM prescriptions for non-chronic diseases (95\% CI, 3.06-3.28) and 1.72 times higher that of PIM prescriptions for chronic neurological diseases, which was the next highest category (95\% CI, 1.64-1.80).

Compared with patients $\geqq 65$ years with oral drug prescriptions only and whose main diagnosis did not meet the criteria for chronic diseases.

\subsection{Analysis of Drugs Prescribed to Patients with Chronic Diseases and Long-term Continuous Exposure to PIM Prescriptions}

Table 3 shows the distribution of drug categories for long-term continuous exposure to PIM in the top four chronic diseases. The most prescribed were the category of central nervous system drugs, accounting for $53.16 \%(68,425)$ of all drugs. Of these, the highest number of prescriptions was for benzodiazepines, which are the most frequently issued drugs for nervous system diseases and mental disorders. The second most frequently prescribed category of drugs was for the treatment of cardiovascular disorders, comprising $20.32 \%$ of the total $(26,157)$, and alpha-1 blockers were the most prescribed.

Table 3. Distribution of long-term continuous exposure to PIM in certain chronic diseases.

\begin{tabular}{|c|c|c|c|c|c|}
\hline PIM & Total $(\%)$ & $\begin{array}{c}\text { Mental } \\
\text { Disorders }\end{array}$ & $\begin{array}{l}\text { Diseases of the } \\
\text { Nervous System }\end{array}$ & $\begin{array}{l}\text { Diseases of the } \\
\text { Circulatory } \\
\text { System }\end{array}$ & $\begin{array}{l}\text { Diseases of the } \\
\text { Digestive } \\
\text { System }\end{array}$ \\
\hline Anti-cholinergics & \multicolumn{5}{|c|}{$6230(4.84 \%)$} \\
\hline First-generation anti-histamines & 3321 & $833(25.08 \%)$ & $437(13.16 \%)$ & $1579(47.55 \%)$ & $472(14.21 \%)$ \\
\hline Anti-Parkinsonian agents & 2159 & $618(28.62 \%)$ & $1006(46.6 \%)$ & $449(20.8 \%)$ & $86(3.98 \%)$ \\
\hline Anti-spasmodics & 750 & $179(23.87 \%)$ & $70(9.33 \%)$ & $299(39.87 \%)$ & $202(26.93 \%)$ \\
\hline Anti-thrombotics & \multicolumn{5}{|c|}{$3416(2.65 \%)$} \\
\hline Ticlopidine & 3416 & $436(12.76 \%)$ & $221(6.47 \%)$ & $2384(69.79 \%)$ & $375(10.98 \%)$ \\
\hline Cardiovascular & \multicolumn{5}{|c|}{$26,157(20.32 \%)$} \\
\hline Peripheral alpha- 1 blockers & 8753 & $1346(15.38 \%)$ & $641(7.32 \%)$ & $5713(65.27 \%)$ & $1053(12.03 \%)$ \\
\hline Central alpha blockers & 935 & $79(8.45 \%)$ & $24(2.57 \%)$ & $623(66.63 \%)$ & $209(22.35 \%)$ \\
\hline Dronedarone & 3288 & $327(9.95 \%)$ & $150(4.56 \%)$ & $2638(80.23 \%)$ & $173(5.26 \%)$ \\
\hline Digoxin & 3181 & $299(9.4 \%)$ & $185(5.82 \%)$ & $2470(77.65 \%)$ & $227(7.14 \%)$ \\
\hline Amiodarone & 935 & $79(8.45 \%)$ & $24(2.57 \%)$ & $623(66.63 \%)$ & $209(22.35 \%)$ \\
\hline Central nervous system & \multicolumn{5}{|c|}{$68,425(53.16 \%)$} \\
\hline $\begin{array}{c}\text { Anti-depressants, alone or in } \\
\text { combination }\end{array}$ & 3501 & $1530(43.7 \%)$ & $428(12.23 \%)$ & $1189(33.96 \%)$ & $354(10.11 \%)$ \\
\hline $\begin{array}{l}\text { Anti-psychotics, first- (conventional) } \\
\text { and second- (atypical) generation }\end{array}$ & 9087 & $4854(53.42 \%)$ & $1223(13.46 \%)$ & $2457(27.04 \%)$ & $553(6.09 \%)$ \\
\hline Benzodiazepines & 45,242 & $17,977(39.74 \%)$ & $5105(11.28 \%)$ & $17,699(39.12 \%)$ & $4461(9.86 \%)$ \\
\hline $\begin{array}{l}\text { Non-benzodiazepine, benzodiazepine } \\
\text { receptor agonist hypnotics }\end{array}$ & 10,588 & $5124(48.39 \%)$ & $773(7.3 \%)$ & $3673(34.69 \%)$ & $1018(9.61 \%)$ \\
\hline Endocrine & \multicolumn{5}{|c|}{$7094(5.51 \%)$} \\
\hline Estrogens with or without progestins & 327 & $92(28.13 \%)$ & $39(11.93 \%)$ & $168(51.38 \%)$ & $28(8.56 \%)$ \\
\hline Insulin, sliding scale & 5389 & $1112(20.63 \%)$ & $633(11.75 \%)$ & $2857(53.02 \%)$ & $787(14.6 \%)$ \\
\hline Megestrol & 5 & $2(40 \%)$ & $0(0 \%)$ & $2(40 \%)$ & $1(20 \%)$ \\
\hline Glyburide & 1373 & $314(22.87 \%)$ & $76(5.54 \%)$ & $751(54.7 \%)$ & $232(16.9 \%)$ \\
\hline Gastrointestinal & \multicolumn{5}{|c|}{$8666(6.73 \%)$} \\
\hline Metoclopramide & 5961 & $1134(19.02 \%)$ & $474(7.95 \%)$ & $2428(40.73 \%)$ & $1925(32.29 \%)$ \\
\hline Proton-pump inhibitors & 2705 & $294(10.87 \%)$ & $106(3.92 \%)$ & $863(31.9 \%)$ & $1442(53.31 \%)$ \\
\hline Pain medications & \multicolumn{5}{|c|}{$5435(4.22 \%)$} \\
\hline Non-selective cyclooxygenase inhibitors & 3300 & $809(24.52 \%)$ & $488(14.79 \%)$ & $1581(47.91 \%)$ & $422(12.79 \%)$ \\
\hline Indomethacin & 217 & $39(17.97 \%)$ & $12(5.53 \%)$ & $110(50.69 \%)$ & $56(25.81 \%)$ \\
\hline Skeletal muscle relaxants & 1918 & $502(26.17 \%)$ & $285(14.86 \%)$ & $824(42.96 \%)$ & $307(16.01 \%)$ \\
\hline Genitourinary & \multicolumn{5}{|c|}{$3300(2.56)$} \\
\hline Desmopressin & 3300 & $173(5.24 \%)$ & $73(2.21 \%)$ & $264(8 \%)$ & $133(4.03 \%)$ \\
\hline
\end{tabular}




\section{Discussion}

\subsection{Subject Characteristics}

Previous studies on PIM prescriptions to the elderly showed that sex, age, co-morbidity and polypharmacy were significant factors affecting the prescribed patients [17,18,26-28]. Those results are similar to the results of the present study (Table 1). Although the correlation between sex and the incidence of PIM did not reach statistical significance $(p=0.576)$, the percentage of PIM prescribed to women was higher than the percentage prescribed to men (54.55\% vs. $45.45 \%)$.

The fact that cardiology departments issued PIM prescriptions to the highest number of patients $(3,523)$ in this study was in line with the findings of a 2015 study on the prevalence of PIM prescribed to hospitalized patients older than 65 years [29]. However, the highest incidence occurred in psychiatric departments $(88.43 \%)$. The results are similar to those of Lang et al., who reported that the PIM prevalence rate in psychiatric inpatients or outpatients was as high as $53.0 \%$ [30].

\subsection{Long-term Exposure to PIM Prescriptions Amongst Patients with Various Chronic Diseases}

People age 65 years and older, with at least one chronic disease are usually multiple medication users [9,10,17,18,31-33]. The proportion who take at least one PIM is between 22 and 56\% [34,35]. Thus, the elderly have long been in serious danger of exposure to PIM. Our study went a step further and explored the long-term risks of PIM exposure amongst the community-dwelling elderly with chronic diseases. Our study shows that $52.96 \%$ of chronically ill elderly people in the communities were taking PIM; patients with chronic mental disorders were the most likely to have at least one PIM on every prescription $(40.05 \%)$. This shows that out of all chronic diseases, patients with mental disorders are at the greatest risk of being prescribed PIM. Compared to patients with non-chronic diseases, the OR for being prescribed PIM due to mental disorders was at least double that of any other disease (Table 2). This finding is worthy of clinicians' attention.

Many studies proved high correlations between chronic mental disorders and PIM prescriptions, which is in exact accordance with the findings of this study. Yang et al. studied the relationship between elderly patients with chronic diseases or disabilities and PIM prescriptions. The results showed a significant correlation between prescriptions for PIM and the presence of a mental disorder $(p<0.001)$ [33]. Vieira de Lima et al. also showed that a mental disorder diagnosis was one of the factors that contributed to the high rate of PIM prescriptions amongst the elderly in institutions [36]. Swanoski et al. found that the incidence of PIM prescriptions amongst patients with diabetes was higher than that for depression, which differs from the findings of this and other studies [28]. This may result from their investigation of only three chronic diseases-diabetes, arthritis and depression. Compared to the broad number of chronic diseases reviewed in the current study, the investigation of a different sample group inevitably produced different results. The incidence of long-term continuous exposure to PIM prescriptions was second-highest in neurological diseases. This is in accordance with past studies by Tsai et al. that identified neurological patients with cognitive impairments as having a higher risk of exposure to PIM to hence the general population [37].

\subsection{Correlation between Different Chronic Diseases and PIM}

As shown in Table 3, prescriptions for CNS category medications accounted for more than half (53.16\%) of all drug categories, and benzodiazepines were the most commonly prescribed, with 45,242 records, constituting about $35.15 \%$ of the total. This finding is similar to those of past research $[17,38,39]$. These drugs are commonly used to treat anxiety, psychological distress, and/or insomnia in the elderly. Age-related changes in the elderly can also influence an individual's pharmacokinetics and pharmacodynamics [39]. This is the main reason why the elderly are prone to unexpected adverse effects after taking these drugs. There is also a high incidence of adverse drug events (ADEs) caused by anti-psychotic drug use amongst outpatients [40]. In particular, drugs with inhibitory effects on the CNS often lead to sedation, extrapyramidal symptoms, dizziness and ataxia and account for more 
than $55 \%$ of ADEs. In addition, most anti-psychotic drugs are metabolized by the hepatic cytochrome P450 system, and patients who are taking drugs that compete metabolically with anti-psychotics can experience potentially harmful drug interactions [41]. Hence, the aforementioned commonly prescribed mental disorder drugs present high potential risk to the elderly.

Cardiovascular drugs were the second most frequent PIM in this study. The most commonly prescribed were alpha- 1 blockers, such as doxazosin, terazosin and tamsulosin. These are recommended agents for treating hypertension with benign prostate hypertrophy. However, they carry potential ADEs such as postural hypotension and dizziness; hence, they are not recommended in elderly patients on routine hypertension treatment. If these medications are necessary for the treatment of prostatic hypertrophy, patients should be advised to take them before going to bed. Otherwise, alternative medications are recommended whenever possible. Metoclopramide was the most commonly prescribed drug for digestive tract diseases. The potential risk of tardive dyskinesia for elderly using metoclopramide is common [42]; thus, it is suggested that metoclopramide be replaced with other drugs if necessary.

\subsection{Differences between Beers Criteria 2019 and 2015}

The American Geriatrics Society updated the Beers Criteria in 2019, removing Ticlopidine and Pentazocine because they were no longer on the US market, and adding Glimepiride, Methylscopolamine and Pyrilamine [43]. When the Beers Criteria were updated in 2015, they could be immediately applied to the Taiwan environment, because there were no substantial differences in the pharmaceuticals available on the market. However, Ticlopidine is still widely used in Taiwan. Therefore, use of the 2019 version of the Beers Criteria 2019 to determine the rationality of prescriptions in the Taiwan context may have resulted in Ticlopidine being overlooked, and exposed elderly patients to unsafe antithrombotic drugs.

\subsection{Limitations of the Study}

This study was aimed at evaluating community-dwelling elderly with chronic diseases, and the study population was not drawn from all areas of Taiwan. However, we tried to avoid an over-concentration of drug prescription data from any one kind of medical institution and ensured that the prescriptions originated from all healthcare organization levels, including hospitals and community clinics, to obtain more objective data. Therefore, we believe that the results of this study may represent the current state of PIM use amongst elderly patients with chronic diseases in Taiwan. In subsequent studies, we will further address and evaluate the clinical outcomes and relative risks amongst patients taking PIMs.

\section{Conclusions}

The probability of PIM prescriptions in the elderly with chronic diseases was significantly correlated with age, sex, co-morbidity and polypharmacy. The mental disorders category had the highest rate of long-term persistent exposure to PIM. The most common prescriptions for PIM were in the CNS category, with benzodiazepines being the most frequently dispensed. Drug safety concerns should be closely monitored in the elderly with the abovementioned conditions.

Author Contributions: Conceptualization, T.W., H.W., and H.L.; methodology, all authors.; software, H.L. and K.H.; validation, all authors; formal analysis, H.L. and K.H.; investigation, all authors.; resources, T.W., P.G., and K.H.; data curation, H.L., K.H.; writing-original draft preparation, H.W. and K.H.; writing—review and editing, T.W., H.L., P.G., and D.T.; visualization, T.W., H.W. H.L. and K.H.; supervision, T.W. P.G.; project administration, T.W.; all authors have read and approved the final version of the manuscript.

Funding: This research received no external funding.

Conflicts of Interest: The authors declare no conflict of interest. 


\section{References}

1. Kaufman, D.W.; Kelly, J.P.; Rosenberg, L.; Anderson, T.E.; Mitchell, A.A. Recent patterns of medication use in the ambulatory adult population of the United States: The Slone survey. JAMA 2002, 287, 337-344. [CrossRef] [PubMed]

2. Barat, I.; Andreasen, F.; Damsgaard, E.M.S. The consumption of drugs by 75-year-old individuals living in their own homes. Eur. J. Clin. Pharmacol. 2000, 56, 501-509. [CrossRef]

3. Bertoldi, A.D.; Barros, A.J.; Hallal, P.C.; Lima, R.C. Drug utilization in adults: Prevalence and individuals determinants. Rev. Saude Publica 2004, 38, 228-238. [CrossRef] [PubMed]

4. Ribeiro, A.Q.; Rozenfeld, S.; Klein, C.H.; César, C.C.; Acurcio, F.D. A survey on medicine use by elderly retirees in Belo Horizonte, Southeastern Brazil. Rev. Saude Publica 2008, 42, 724-732. [CrossRef] [PubMed]

5. Rozenfeld, S.; Fonseca, M.J.; Acurcio, F.A. Drug utilization and polypharmacy among the elderly: A survey in Rio de Janeiro City, Brazil. Rev. Panam. Salud Publica 2008, 23, 34-43. [CrossRef] [PubMed]

6. Beers, M.; Baran, R.; Frenia, K. Drugs and the elderly, Part 1: The problems facing managed care. Am. J. Manag. Care 2000, 6, 1313-1320. [PubMed]

7. Chang, C.-B.; Chan, D.-C. Comparison of published explicit criteria for potentially inappropriate medications in older adults. Drugs Aging 2010, 27, 947-957. [CrossRef]

8. Jano, E.; Aparasu, R.R. Healthcare outcomes associated with beers' criteria: A systematic review. Ann. Pharmacother. 2007, 41, 438-448. [CrossRef]

9. Spinewine, A.; Schmader, K.E.; Barber, N.; Hughes, C.; Lapane, K.L.; Swine, C.; Hanlon, J.T. Appropriate prescribing in elderly people: How well can it be measured and optimised? Lancet 2007, 370, 173-184. [CrossRef]

10. Bahat, G.; Ilhan, B.; Bay, I.; Avci, S.; Tufan, F.; Kilic, C.; Karan, M. Comparing the explicit tools vs. Implicit evaluation among turkish geriatric outpatients. Innov. Aging 2017, 1, 1048. [CrossRef]

11. By the American Geriatrics Society Beers Criteria Update Expert Panel, American Geriatrics Society 2015 Updated Beers Criteria for Potentially Inappropriate Medication Use in Older Adults. J. Am. Geriatr. Soc. 2015, 63, 2227-2246. [CrossRef] [PubMed]

12. Fick, D. Potentially Inappropriate Medication Use in a Medicare Managed Care Population: Association with Higher Costs and Utilization. J. Manag. Care Pharm. 2001, 7, 407-413. [CrossRef]

13. Hyttinen, V.; Jyrkkä, J.; Valtonen, H. A Systematic Review of the Impact of Potentially Inappropriate Medication on Health Care Utilization and Costs Among Older Adults. Med. Care 2016, 54, 950-964. [CrossRef] [PubMed]

14. Reich, O.; Rosemann, T.; Rapold, R.; Blozik, E.; Senn, O. Potentially inappropriate medication use in older patients in Swiss managed care plans: Prevalence, determinants and association with hospitalization. PLoS ONE 2014, 9, e105425. [CrossRef] [PubMed]

15. Ruggiero, C.; Dell'Aquila, G.; Gasperini, B.; Onder, G.; Lattanzio, F.; Volpato, S.; Corsonello, A.; Maraldi, C.; Bernabei, R.; Cherubini, A. Potentially inappropriate drug prescriptions and risk of hospitalization among older, Italian, nursing home residents: The ULISSE project. Drugs Aging 2010, 27, 747-758. [CrossRef] [PubMed]

16. Lai, H.Y.; Hwang, S.J.; Chen, Y.C.; Chen, T.J.; Lin, M.H.; Chen, L.K. Prevalence of the prescribing of potentially inappropriate medications at ambulatory care visits by elderly patients covered by the Taiwanese National Health Insurance program. Clin. Ther. 2009, 31, 1859-1870. [CrossRef]

17. Nam, Y.-S.; Han, J.S.; Kim, J.Y.; Bae, W.K.; Lee, K. Prescription of potentially inappropriate medication in Korean older adults based on 2012 Beers Criteria: A cross-sectional population based study. BMC Geriatr. 2016, 16, 118. [CrossRef]

18. Lin, H.Y.; Liao, C.C.; Cheng, S.H.; Wang, P.C.; Hsueh, Y.S. Association of potentially inappropriate medication use with adverse outcomes in ambulatory elderly patients with chronic diseases: Experience in a Taiwanese medical setting. Drugs Aging 2008, 25, 49-59. [CrossRef]

19. Chu, H.Y.; Chen, C.C.; Cheng, S.H. Continuity of care, potentially inappropriate medication, and health care outcomes among the elderly: Evidence from a longitudinal analysis in Taiwan. Med. Care 2012, 50, 1002-1009. [CrossRef] 
20. Lu, W.H.; Wen, Y.W.; Chen, L.K.; Hsiao, F.Y. Effect of polypharmacy, potentially inappropriate medications and anticholinergic burden on clinical outcomes: A retrospective cohort study. CMAJ 2015, 187, e130-e137. [CrossRef]

21. Jacob, L.; Breuer, J.; Kostev, K. Prevalence of chronic diseases among older patients in German general practices. Ger. Med. Sci. 2016, 14, 3.

22. Marengoni, A.; Winblad, B.; Karp, A.; Fratiglioni, L. Prevalence of chronic diseases and multimorbidity among the elderly population in Sweden. Am. J. Public Health 2008, 98, 1198-1200. [CrossRef]

23. Wu, F.; Guo, Y.; Kowal, P.; Jiang, Y.; Yu, M.; Li, X.; Zheng, Y.; Xu, J. Prevalence of major chronic conditions among older Chinese adults: The Study on Global AGEing and adult health (SAGE) wave 1. PLoS ONE 2013, 8, e74176. [CrossRef] [PubMed]

24. Benjamin, R.M. Multiple chronic conditions: A public health challenge. Public Health Rep. 2010, 125, 626-627. [CrossRef] [PubMed]

25. National Health Insurance Administration List of Chronic Disease Included. Available online: https: //www.nhi.gov.tw/Content_List.aspx?n=0205B47A1C459B5A\&topn=D39E2B72B0BDFA15 (accessed on 20 April 2019).

26. Guaraldo, L.; Cano, F.G.; Damasceno, G.S.; Rozenfeld, S. Inappropriate medication use among the elderly: A systematic review of administrative databases. BMC Geriatr. 2011, 11, 79. [CrossRef] [PubMed]

27. Sheikh-Taha, M.; Dimassi, H. Potentially inappropriate home medications among older patients with cardiovascular disease admitted to a cardiology service in USA. BMC Cardiovasc. Disord. 2017, 17, 189. [CrossRef] [PubMed]

28. Swanoski, M.T.; Little, M.M.; St Hill, C.A.; Ware, K.B.; Chapman, S.; Lutfiyya, M.N. Potentially Inappropriate Medication Prescribing in U.S. Older Adults with Selected Chronic Conditions. Consult. Pharm. 2017, 32, 525-534. [CrossRef]

29. Kanagasanthosh, K.; Topno, I.; Aravindkumar, B. Prevalence of potentially inappropriate medication use and drug utilization pattern in elderly patients: A prospective study from a tertiary care hospital. Int. J. Res. Med. Sci. 2017, 3, 11. [CrossRef]

30. Lang, P.O.; Hasso, Y.; Drame, M.; Vogt-Ferrier, N.; Prudent, M.; Gold, G.; Michel, J.P. Potentially inappropriate prescribing including under-use amongst older patients with cognitive or psychiatric co-morbidities. Age Ageing 2010, 39, 373-381. [CrossRef]

31. Fu, S.; Huang, N.; Chou, Y.J. Trends in the prevalence of multiple chronic conditions in Taiwan from 2000 to 2010: A population-based study. Prev. Chronic Dis. 2014, 11, E187. [CrossRef]

32. Naughton, C.; Bennett, K.; Feely, J. Regional variation in prescribing for chronic conditions among an elderly population using a pharmacy claims database. Ir. J. Med. Sci. 2006, 175, 32-39. [CrossRef] [PubMed]

33. Yang, P.J.; Lee, Y.T.; Tzeng, S.L.; Lee, H.C.; Tsai, C.F.; Chen, C.C.; Chen, S.C.; Lee, M.C. Potentially Inappropriate Prescribing in Disabled Older Patients with Chronic Diseases: A Screening Tool of Older Persons' Potentially Inappropriate Prescriptions versus Beers 2012 Criteria. Med. Princ. Pract. 2015, 24, 565-570. [CrossRef] [PubMed]

34. Moriarty, F.; Bennett, K.; Fahey, T.; Kenny, R.A.; Cahir, C. Longitudinal prevalence of potentially inappropriate medicines and potential prescribing omissions in a cohort of community-dwelling older people. Eur. J. Clin. Pharmacol. 2015, 71, 473-482. [CrossRef] [PubMed]

35. Zhan, C.; Sangl, J.; Bierman, A.S.; Miller, M.R.; Friedman, B.; Wickizer, S.W.; Meyer, G.S. Potentially inappropriate medication use in the community-dwelling elderly: Findings from the 1996 Medical Expenditure Panel Survey. JAMA 2001, 286, 2823-2829. [CrossRef] [PubMed]

36. Vieira de Lima, T.J.; Garbin, C.A.; Garbin, A.J.; Sumida, D.H.; Saliba, O. Potentially inappropriate medications used by the elderly: Prevalence and risk factors in Brazilian care homes. BMC Geriatr. 2013, 13, 52. [CrossRef] [PubMed]

37. Tsai, R.; Noone, M.; Johnson, B.; Pradeep, V.G.; Verghese, J. Potentially inappropriate medication use in individuals with mild cognitive impairment: Results from the Kerala Einstein Study. J. Am. Geriatr. Soc. 2012, 60, 1369-1370. [CrossRef]

38. De Jong, M.R.; Van der Elst, M.; Hartholt, K.A. Drug-related falls in older patients: Implicated drugs, consequences, and possible prevention strategies. Ther. Adv. Drug Saf. 2013, 4, 147-154. [CrossRef]

39. Lindsey, P.L. Psychotropic medication use among older adults: What all nurses need to know. J. Gerontol. Nurs. 2009, 35, 28-38. [CrossRef] 
40. Kumar, N.; Sharma, S.; Kapoor, V. Adverse Drug Events in Patients with Mental Disorder in an Ambulatory Setting. Int. J. Appl. Basic Med. Res. 2017, 7, 108-111. [CrossRef]

41. Guo, J.J.; Wu, J.; Kelton, C.M.; Jing, Y.; Fan, H.; Keck, P.E.; Patel, N.C. Exposure to potentially dangerous drug-drug interactions involving antipsychotics. Psychiatr. Serv. 2012, 63, 1080-1088. [CrossRef]

42. Stewart, R.B.; Cerda, J.J.; Moore, M.T.; Hale, W.E. Metoclopramide: An analysis of inappropriate long-term use in the elderly. Ann. Pharmacother. 1992, 26, 977-979. [CrossRef] [PubMed]

43. By the American Geriatrics Society Beers Criteria Update Expert Panel, American Geriatrics Society 2019 Updated AGS Beers Criteria (R) for Potentially Inappropriate Medication Use in Older Adults. J. Am. Geriatr. Soc. 2019, 67, 674-694. [CrossRef] [PubMed]

(C) 2019 by the authors. Licensee MDPI, Basel, Switzerland. This article is an open access article distributed under the terms and conditions of the Creative Commons Attribution (CC BY) license (http://creativecommons.org/licenses/by/4.0/). 